\title{
A new procedure to estimate BLEVE overpressure
}

\author{
Behrouz Hemmatian, Joaquim Casal, Eulàlia Planas* \\ Centre for Studies on Technological Risks (CERTEC). Department of Chemical Engineering. \\ EEBE. Universitat Politècnica de Catalunya-BarcelonaTech. Eduard Maristany, 10. 08019- \\ Barcelona, Catalonia, Spain
}

\begin{abstract}
Several methodologies, based on different thermodynamic assumptions and requiring substance properties and thermodynamic data, have been proposed in the literature for the prediction of the mechanical energy released by a Boiling Liquid Expanding Vapour Explosion (BLEVE) and the associated overpressure. A new method, simple and easy to use, is presented which only requires the vessel filling degree and the temperature at failure as input variables to estimate this energy. The polynomial approach has been used to obtain the equation corresponding to the diverse substances most commonly involved in these explosions. The comparison of the predicted values with experimental data shows a good agreement.
\end{abstract}

\section{Keywords}

Vessel explosion; explosion energy; blast overpressure; pressure wave.

\section{Introduction}

Boiling Liquid Expanding Vapour Explosions (BLEVEs), a major accident which can have severe consequences, occur from time to time, both in fixed plants and in the transportation of hazardous materials. Overpressure and ejection of vessel fragments are the common effects of such an explosion; these can be followed by a fireball if the substance is flammable.

\footnotetext{
* Corresponding author. Tel.: +34 934011736.

E-mail address: eulalia.planas@upc.edu (E. Planas).
} 
When a vessel undergoes a BLEVE, part of the released mechanical energy is converted into overpressure. There are different methodologies to calculate this mechanical energy, based on diverse thermodynamic assumptions (Planas and Casal, 2015):

- Constant volume energy addition (Brode, 1959)

- Real gas behaviour and isentropic expansion (CCPS, 2010)

- Isothermal expansion (Smith et al., 1996)

- Thermodynamic availability (Crowl, 1991, 1992)

- Ideal gas behaviour and isentropic expansion (Prugh, 1991)

- Real gas behaviour and adiabatic irreversible expansion (Planas et al., 2004; Casal and Salla, 2006)

Comparative analysis show that all methodologies tend to provide conservative (i.e. high) results, except those based on real gas behaviour and adiabatic irreversible expansion, which give values that are less conservative but more realistic (Bubbico and Marchini, 2008; Laboureur et al., 2014; Hemmatian et al., 2017). Most of these methods, however, are somewhat cumbersome to be applied and require many thermodynamic data of the substance involved. As for the one based on the superheating energy (Casal and Salla, 2006), although it is much easier to apply, it does not take into account the contribution of the previously existing vapour, what in some cases - a vessel with low filling degree-could imply a nonnegligible error.

For that reason, a research was performed to provide a new methodology to calculate the mechanical energy released during a BLEVE phenomenon, easy and fast to implement and, at least, as reliable and precise as the currently existing ones. In this paper a new procedure is therefore presented, which is based on the thermodynamic assumption of real gas behaviour and adiabatic irreversible expansion but that only requires as input data the vessel filling degree and the temperature at failure. The simplicity of the equations provided allows a fast and accurate estimation of the energy released in the BLEVE of the most common substances undergoing this phenomenon.

\section{BLEVE mechanical energy and its linear behaviour}

When the influence of the diverse thermodynamic assumptions on the calculation of the mechanical energy is analysed, something quite interesting is observed. This is the fact that the model based on real gas behaviour and adiabatic irreversible expansion shows an almost 
linear variation of the energy released as a function of the temperature at the moment of the explosion; this can be seen in Fig. 1 for five substances: propane, butane, methane, water and vinyl chloride. A linearity was also observed at any vessel filling degree $(F D)$; as an example, this is shown in Fig. 2 for the same substances. Here, "filling degree" refers to the liquid filling level at the beginning of the heating process. If there is a loss of containment through, for example, a safety relief valve or a broken pipe, then the filling degree (at initial conditions of pressure and temperature) must be estimated taking into account the mass of material lost during the loss of containment.

This behaviour was found with all the substances investigated, which were -according to a historical analysis (Hemmatian et al., 2015) - the ones more frequently involved in BLEVE accidents.
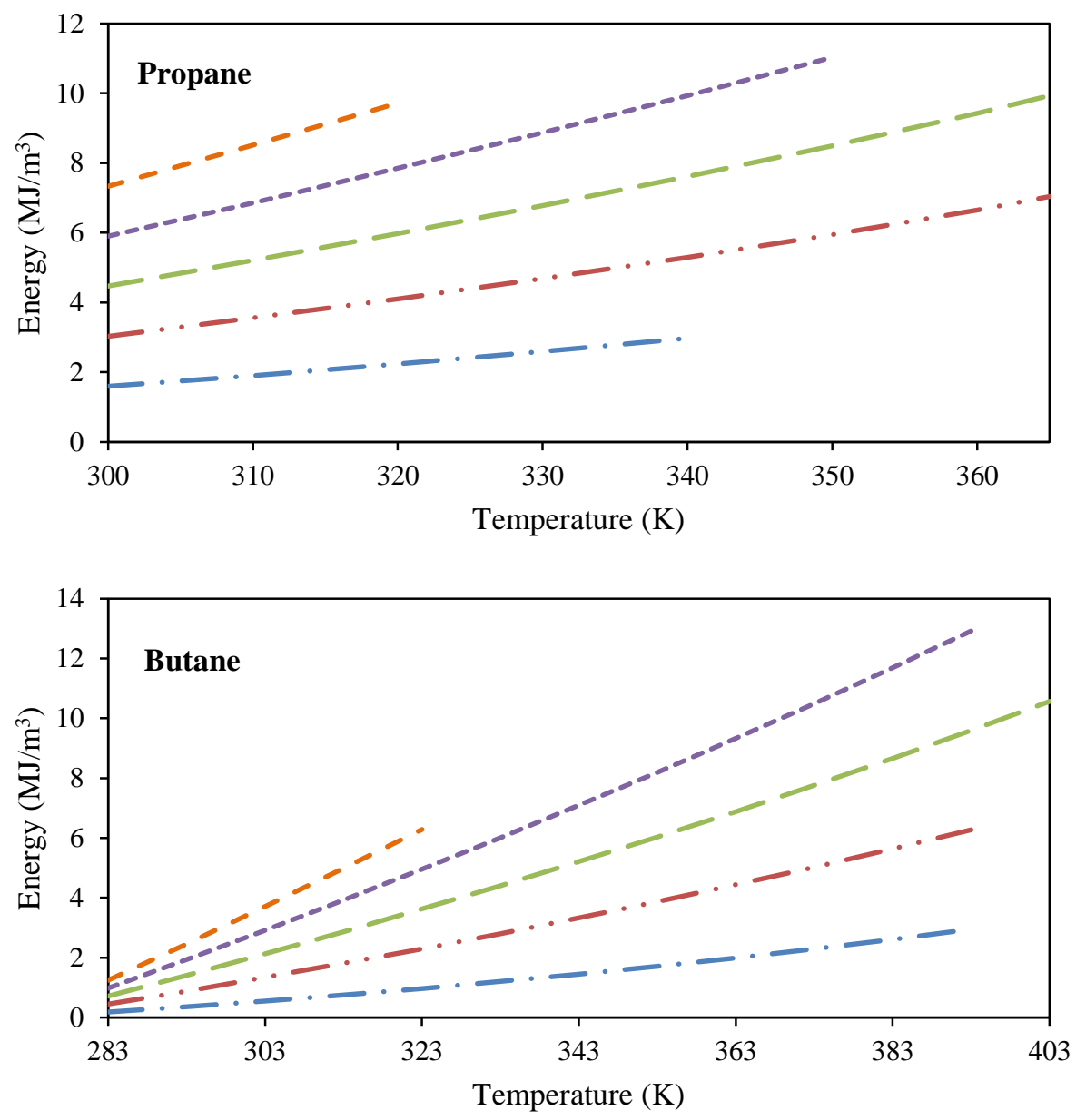

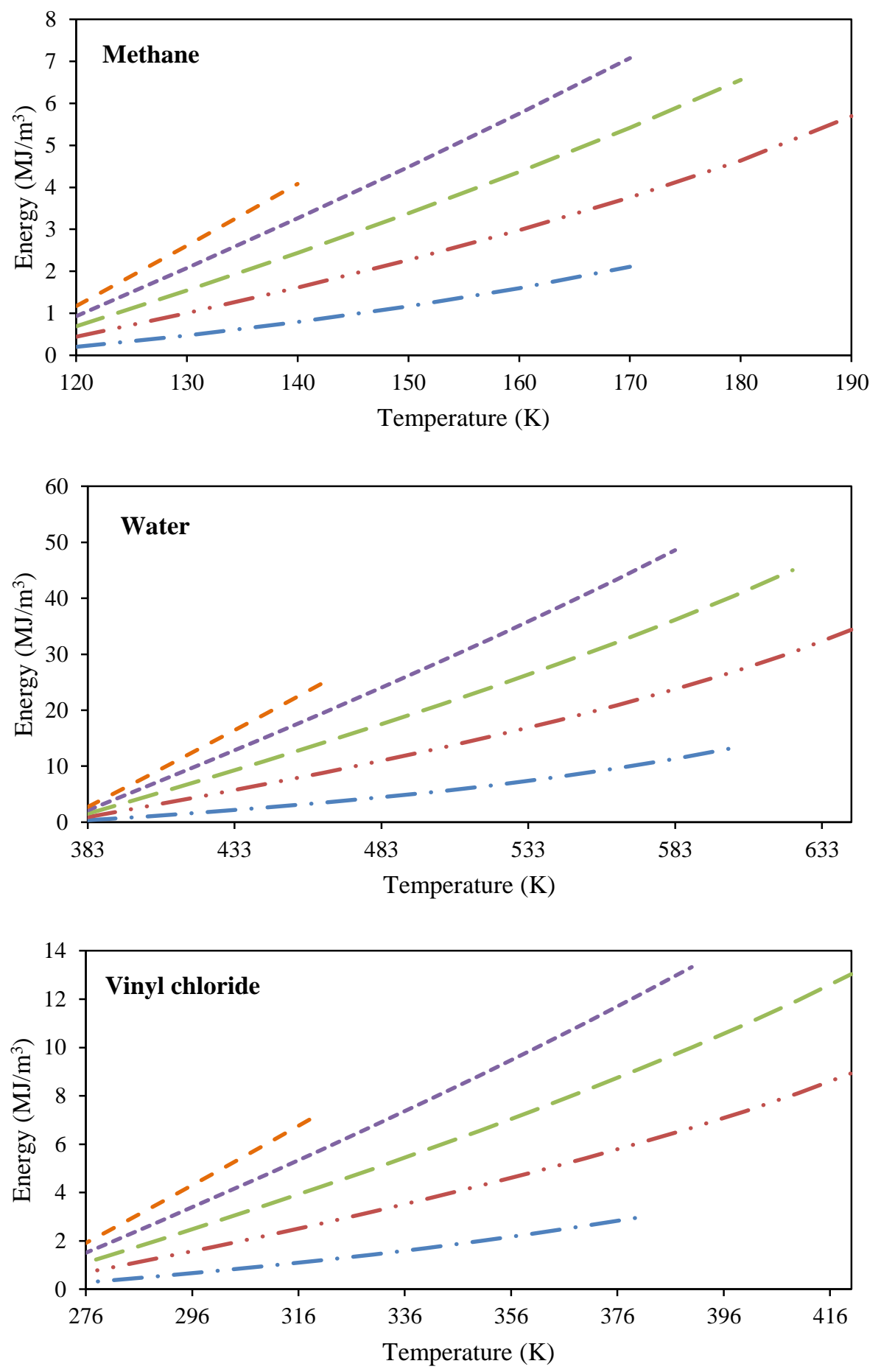

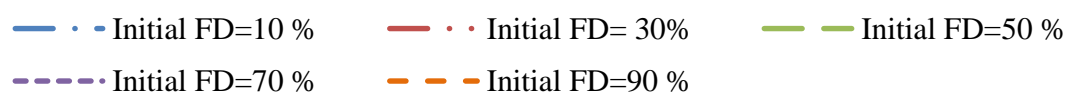


Fig. 1 - Mechanical energy released (per $\mathrm{m}^{3}$ of vessel volume) as a function of the temperature in the vessel at the moment of the explosion, at different filling degrees, based on the real gas behaviour and adiabatic irreversible expansion assumptions.
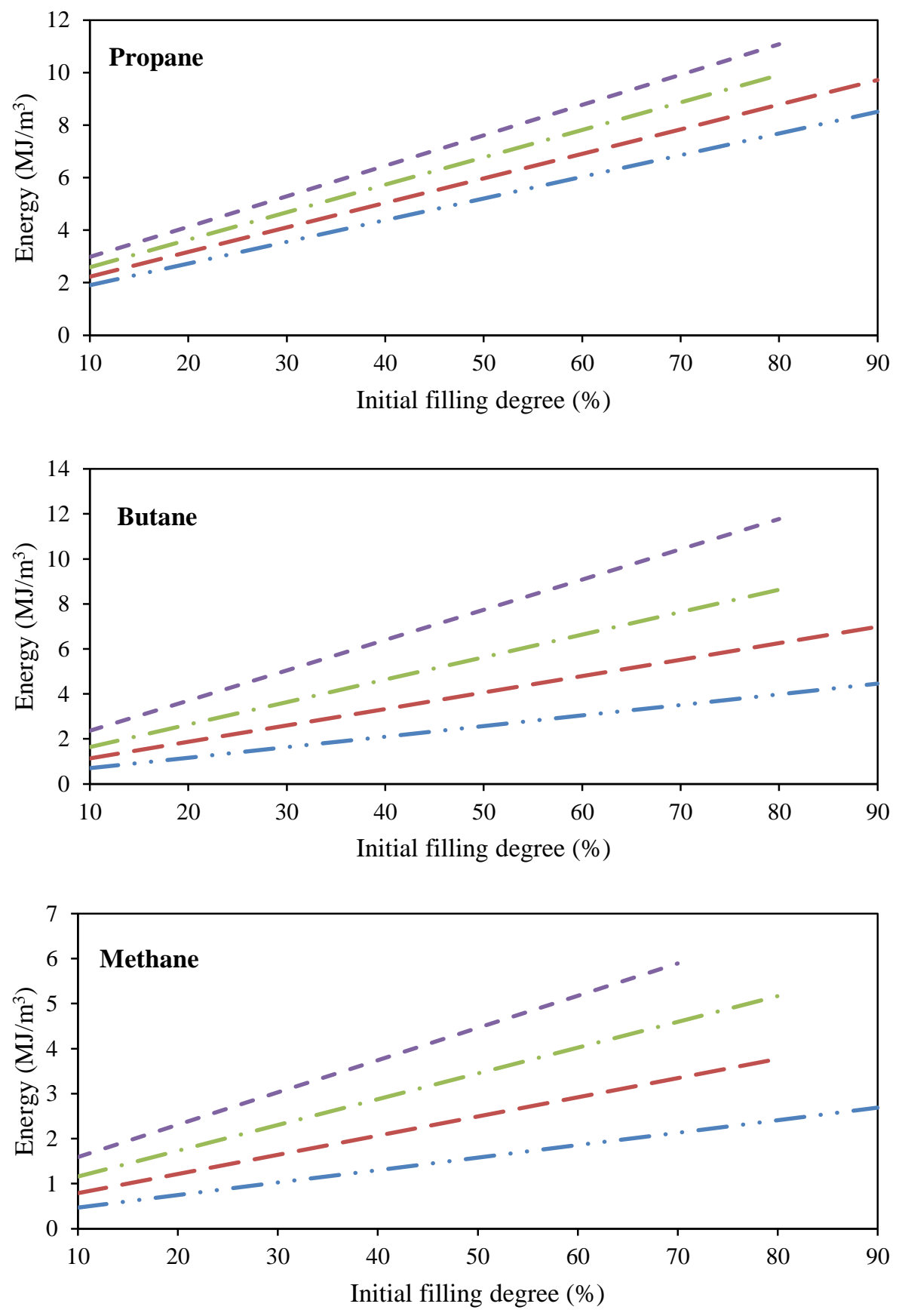

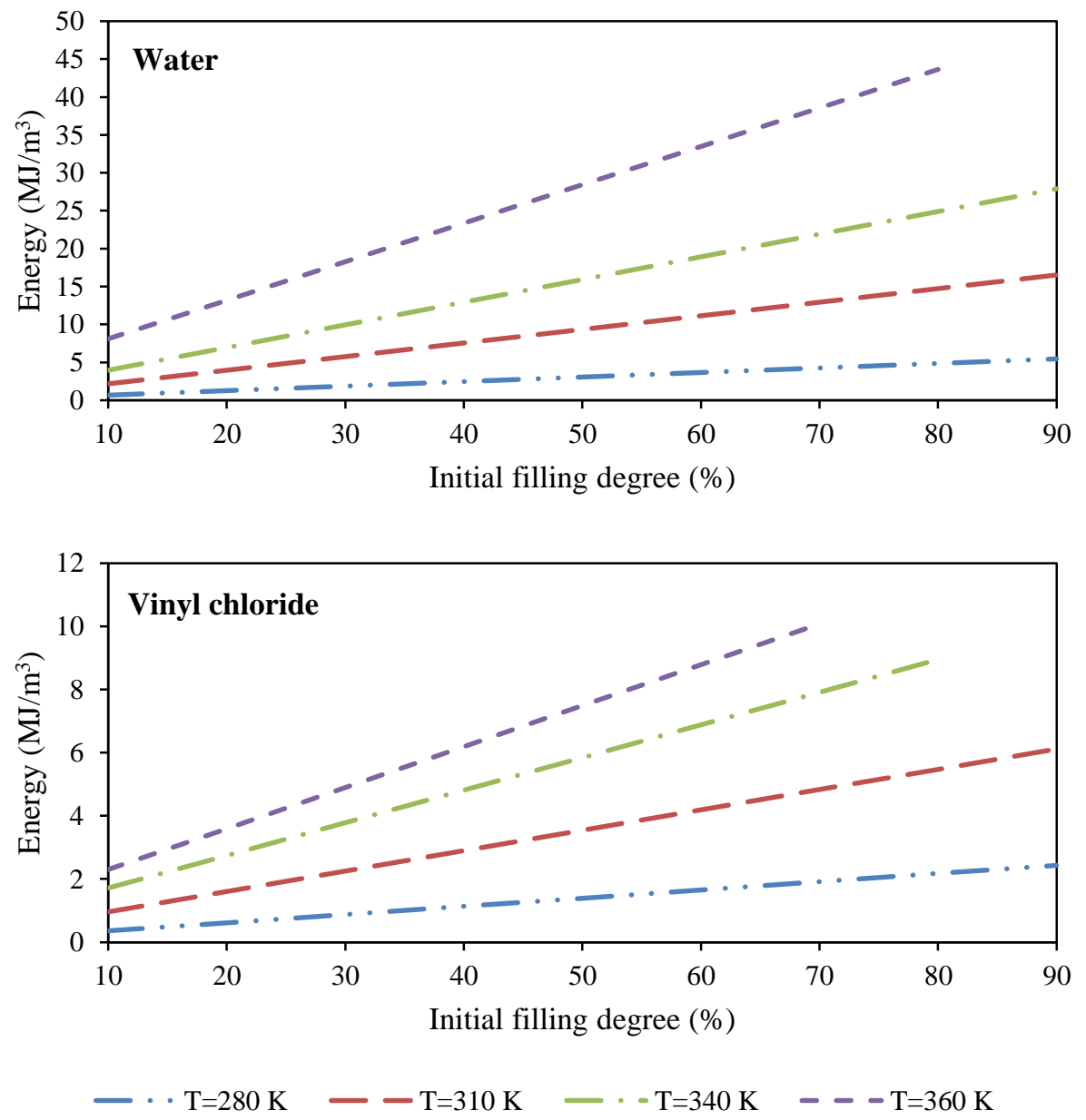

Fig. 2 - Mechanical energy released (per $\mathrm{m}^{3}$ of vessel volume) by the explosion as a function of the filling degree, at different temperatures, based on the real gas behaviour and adiabatic irreversible expansion assumptions, for five different substances.

This linear relationship relating the energy, the temperature and the degree of filling indicates a way to calculate the energy released in a BLEVE and, consequently, the overpressure generated by the explosion. In the following sections, a deeper analysis of this linear behaviour is performed for the substances included in Fig. 1 and Fig. 2 and also for other five involved with a certain frequency in BLEVE accidents.

\section{A new methodology to predict the BLEVE mechanical energy: polynomial approach}

Initially, a set of 2713 scenarios for a $1 \mathrm{~m}^{3}$ vessel (used as a basis for all calculations), covering both different filling degrees (from 1\% to 99\%) and temperatures at the moment of explosion (from storage temperature to the critical one), were defined for the ten substances 
included in Table 1, which are the ones most frequently involved in BLEVE accidents according to a historical analysis (Hemmatian et al., 2015). For all the scenarios, the mechanical energy per $\mathrm{m}^{3}$ of vessel volume was determined by assuming real gas behaviour and adiabatic irreversible expansion, according to the methodology proposed by Planas et al. (2004). The required thermodynamic data were obtained from NIST Reference Fluid Properties, Version 9.1 (Lemmon et al., 2007). A dataset for each substance was therefore prepared with the values of the mechanical energy recorded, together with the final temperature and related filling degree, for each scenario.

However, it should be noticed that some scenarios could not be considered, because the required physical condition was not fulfilled. For example, a container initially filled up to $90 \%$ with liquefied propane at $300 \mathrm{~K}$ could reach its maximum filling degree $(100 \%)$ at a temperature of $326.3 \mathrm{~K}$, before the temperature reached the propane critical one $(369.9 \mathrm{~K})$. This phenomenon is due to the variation of liquid and gas densities as a function of temperature, according to which, at a certain moment, the decreasing gas volume collapses (Casal, 2008) and the vessel becomes completely full of liquid. Therefore, taking this into account, the number of scenarios was finally reduced to 2034 (Table 1).

Table 1. Scenarios used to calculate the mechanical energy for the ten selected substances.

\begin{tabular}{|c|c|c|}
\hline Substance & Filling degree $(\%)$ & Temperature at explosion $(\mathrm{K})$ \\
\hline Propane & $\begin{array}{c}5,10,15,20,25,30,35,40,45,50 \\
55,60,65,70,75,80,85,90\end{array}$ & $300,310,320,330,340,350,360,365$ \\
\hline Butane & $\begin{array}{c}1,5,10,15,20,25,30,35,40,45,50 \\
55,60,65,70,75,80,85,90,95,98 \\
99\end{array}$ & $\begin{array}{c}283,293,303,313,323,333,343,353,363, \\
373,383,393,403\end{array}$ \\
\hline Methane & $\begin{array}{c}5,10,15,20,25,30,35,40,45,50 \\
55,60,65,70,75,80,85,90\end{array}$ & $120,130,140,150,160,170,180$ \\
\hline Water & $10,20,30,40,50,60,70,80,90$ & $\begin{array}{c}383,403,423,443,463,483,503,523,543 \\
563,583,603,623\end{array}$ \\
\hline $\begin{array}{l}\text { Vinyl } \\
\text { chloride }\end{array}$ & $\begin{array}{c}1,5,10,15,20,25,30,35,40,45,50 \\
55,60,65,70,75,80,85,90,95,98 \\
99\end{array}$ & $\begin{array}{c}270,280,290,300,310,320,330,340,350, \\
360,370,380,390,400,410,420\end{array}$ \\
\hline $\begin{array}{l}\text { Ethylene } \\
\text { oxide }\end{array}$ & $\begin{array}{c}1,5,10,15,20,25,30,35,40,45,50 \\
55,60,65,70,75,80,85,90,95,98 \\
99\end{array}$ & $\begin{array}{l}290,300,310,320,330,340,350,360,370, \\
380,390,400,410,420,430,440,450,460\end{array}$ \\
\hline Propylene & $\begin{array}{c}1,5,10,15,20,25,30,35,40,45,50 \\
55,60,65,70,75,80,85,90,95,98 \\
99\end{array}$ & $\begin{array}{c}235,245,255,265,275,285,295,305,315 \\
325,335,345,355,360\end{array}$ \\
\hline
\end{tabular}




$\begin{array}{ccc} & 1,5,10,15,20,25,30,35,40,45,50, & 250,260,270,280,290,300,310,320,330, \\ \text { Ammonia } & 55,60,65,70,75,80,85,90,95,97, & 340,350,360,370,380,390,400 \\ & 98,99 & \\ \text { Chlorine } & 1,5,10,15,20,25,30,35,40,45,50, & 250,260,270,280,290,300,310,320,330, \\ & 55,60,65,70,75,80,85,90,95,98, & 340,350,360,370,380,390,400,410 \\ & 99 & \\ \text { Ethylene } & 55,60,65,70,75,80,85,90,95,98, & 180,190,200,210,220,230,240,250,260, \\ & 99 & 270,280\end{array}$

In order to fit an appropriate surface to data in a plot of energy as a function of temperature and filling degree, we used MATLAB Curve Fitting Toolbox 3.4.1; an appropriate surface was found by using the polynomial regression model.

While the "best" equations (i.e., those keeping a relatively simple expression) were found by using polynomial expressions, it was necessary to check how they achieved a good fit. The visual examination or a graphical method was the first basic applied approach to see how the surfaces were close to the calculated data and where potential deviations occurred; afterwards, a statistical method was also used to evaluate the goodness-of-fit for the proposed equations.

The four goodness-of-fit statistics parameters used were:

- The sum of squares due to error (SSE)

- R-square

- Adjusted R-square

- Root-mean-square error (RMSE).

In this analysis, the filling degree $(F D)$ and the temperature $(T)$ were considered as input variables, and the related mechanical energy was considered as an output one. The Curve Fitting Toolbox provided different polynomials of the two input variables.

The multiple fits tested were compared through the aforementioned parameters. Table 2 summarizes the mean goodness-of-fit results for the different substances. In this Table, Poly 11 means first degree polynomial for both variables, Poly 12 means first degree polynomial for $F D$ and second degree for temperature, etc. According to these results, the suggested surface model based on Poly13 showed the best performance, as it gives smaller values of the Root Mean Square Error (RMSE) and Sum of Square Error (SSE).

Table 2. Average of Goodness-of-fit statistics parameters for different polynomial degrees. 


\begin{tabular}{ccccc}
\hline Average Poly $($ FD, $\mathbf{T})$ & SSE & $\mathbf{R}^{\mathbf{2}}$ & Adjusted $\mathbf{R}^{2}$ & RMSE \\
\hline Poly 11 & 499.09 & 0.93412 & 0.93342 & 1.31705 \\
Poly 12 & 69.97 & 0.98937 & 0.98913 & 0.50737 \\
Poly 13 & 8.6 & 0.99887 & 0.99881 & 0.17280 \\
Poly 21 & 70.26 & 0.98924 & 0.9890 & 0.51007 \\
Poly 31 & 69.51 & 0.98938 & 0.98901 & 0.51031 \\
Poly 22 & 69.01 & 0.98941 & 0.98912 & 0.50695 \\
\hline
\end{tabular}

Finally, a set of the best equations for predicting the mechanical energy per cubic meter of total vessel volume $(e)$ as a function of the filling degree $(F D)$ and the temperature at the moment of the explosion $(T)$ were obtained by this procedure (Table 3 ).

Table 3. Mechanical energy released per cubic meter of vessel as a function of explosion temperature and initial filling degree (expressed in parts per unit instead of percentage) for different substances.

\begin{tabular}{|c|c|}
\hline Substance & Equation; $e\left(\mathbf{M J} / m^{3}\right) ; T(\mathrm{~K}) ; F D$ \\
\hline Propane & $\begin{array}{c}e=43.97-213.9 \cdot F D-0.152 \cdot T+1.349 \cdot F D \cdot T-0.0004361 \cdot T^{2}-0.002045 \cdot F D \cdot T^{2} \\
+1.55 \cdot 10^{-6} \cdot T^{3}\end{array}$ \\
\hline Butane & $\begin{aligned} e=21.32-87.2 \cdot & F D-0.136 \cdot T+0.4765 \cdot F D \cdot T+0.0001885 \cdot T^{2}-0.0005805 \cdot F D \cdot T^{2} \\
& +9.693 \cdot 10^{-6} T^{3}\end{aligned}$ \\
\hline Methane & $\begin{aligned} e=6.13-42.71 \cdot & F D-0.06558 \cdot T+0.5629 \cdot F D \cdot T-0.0001499 \cdot T^{2}-0.001647 \cdot F D \cdot T^{2} \\
& +2.327 \cdot 10^{-6} \cdot T^{3}\end{aligned}$ \\
\hline Water & $\begin{array}{c}e=56.36-275.6 \cdot F D-0.2341 \cdot T+1.076 \cdot F D \cdot T+0.0001696 \cdot T^{2}-0.0009183 \cdot F D \cdot T^{2} \\
+1.626 \cdot 10^{-6} T^{3}\end{array}$ \\
\hline Vinyl chloride & $\begin{array}{c}e=20.71-92.48 \cdot F D-0.1206 \cdot T+0.5346 \cdot F D \cdot T+9.836 \cdot 10^{-5} \cdot T^{2}-0.0006987 \cdot F D \cdot T^{2} \\
+2.503 \cdot 10^{-7} T^{3}\end{array}$ \\
\hline Ethylene oxide & $\begin{aligned} e=23.61-119.4 & \cdot F D-0.1182 \cdot T+0.6295 \cdot F D \cdot T+4.505 \cdot 10^{-5} \cdot T^{2}-0.0007463 \cdot F D \cdot T^{2} \\
& +2.946 \cdot 10^{-7} \cdot T^{3}\end{aligned}$ \\
\hline Propylene & $\begin{array}{c}e=104.9-86.15 \cdot F D-1.035 \cdot T+0.5013 \cdot F D \cdot T+0.00329 \cdot T^{2}-0.0005726 \cdot F D \cdot T^{2} \\
-3.321 \cdot 10^{-6} \cdot T^{3}\end{array}$ \\
\hline Ammonia & $\begin{array}{c}e=28.34-168.4 \cdot F D-0.1447 \cdot T+1.048 \cdot F D \cdot T-6.71 \cdot 10^{-5} \cdot T^{2}-0.001471 \cdot F D \cdot T^{2} \\
+7.984 \cdot 10^{-7} \cdot T^{3}\end{array}$ \\
\hline Chlorine & $\begin{array}{c}e=-2.469-81.17 \cdot F D+0.08234 \cdot T+0.4975 \cdot F D \cdot T-0.0005088 \cdot T^{2}-0.0006739 \cdot F D \\
\cdot T^{2}+8.889 \cdot 10^{-7} \cdot T^{3}\end{array}$ \\
\hline Ethylene & $\begin{array}{c}e=9.356-69.53 \cdot F D-0.04289 \cdot T+0.6194 \cdot F D \cdot T-0.0003058 \cdot T^{2}-0.001262 \cdot F D \cdot T^{2} \\
+1.454 \cdot 10^{-6} \cdot T^{3}\end{array}$ \\
\hline
\end{tabular}


A slightly better fitting could probably have been reached by using more complex polynomial expressions; however, the objective was to find a methodology that, while being accurate, was also simple and practical to be applied; these expressions fulfil both conditions.

To go from energy to overpressure, the total vessel volume has to be multiplied by " $e$ " in order to find the total amount of mechanical energy released by a given system. Then, the total energy can be converted to the equivalent TNT mass $\left(m_{T N T}\right)$ and afterwards into overpressure by means of the corresponding conversion graph. A factor $\beta=0.4$ can be applied to take into account the fact that an important amount of energy will be devoted to break the vessel (ductile failure) (Casal, 2008); this implies that only $40 \%$ of the energy released is invested in creating the overpressure.

\section{Comparative study}

We checked the equations obtained (Table 3) by comparing them with two sets of experimental data from Johnson et al. (1990) and Birk et al. (2006, 2007) (second column of Table 4) (the directional effect at short distances (Birk and VanderSteen, 2006; Birk et al., 2016) was not considered). We also add the comparison of the original real gas behaviour and adiabatic irreversible expansion (RAIE) method proposed by Planas et al. (2004) (first column of Table 4) with the same set of experimental values. The resulting overpressures at different distances corresponding to each method were obtained from the TNT equivalent mass and the well-known plot of the scaled distance vs. peak overpressure for TNT.

The root-mean-square deviation (RMSD) (Piñeiro et al., 2008) was used as a statistical parameter to perform a comparative analysis between the two methods and the average values of the aforementioned experimental data. As it is shown in Table 4, the new method here proposed gave a good accuracy as compared to the experimental data from Johnson et al. (1990) and Birk et al. (2006, 2007).

The new approach gives results similar to those from RAIE method (from which it has been developed) and sometimes even better; for example, the RMSE value for the Birk experiments is lower for the new approach than the RAIE value (Table 4). Actually, Table 4 shows that the approach based on the polynomial method has some degree of deviation from the data set from which the equations were derived, because the fitting method passes a surface from the minimum distance to a data point. This deviation could be larger in some points based on the fitted surface and its distance to the data points and the degree of polynomial. Theoretically, the new method and the RAIE approach should give the same RMSD value. The difference shown in Table 4 is due to the partial non-linear behaviour (later 
commented) shown in Fig. 3; in fact, it is this "error" what improves de value of RMSD for the new method.

Table 4. Root Mean Square Deviation (RMSD) values for different methods based on their thermodynamic assumptions

\begin{tabular}{lcc}
\hline RMSD & $\begin{array}{c}\text { Real gas behaviour and } \\
\text { adiabatic irreversible } \\
\text { expansion* }\end{array}$ & $\begin{array}{c}\text { New approach } \\
\text { (polynomial)* }\end{array}$ \\
\hline Johnson & 2.3 & 2.2 \\
Birk & 4.9 & 4.2 \\
\hline * Using the TNT vs. scaled distance curve &
\end{tabular}

The nonlinear relation between temperature and filling degree (shown in Fig. 3) is the reason for the observed deviation in the polynomial equations that, as seen in the comparative analysis, remains in the range of the expected accuracy of this type of calculation and, therefore, should be considered acceptable.

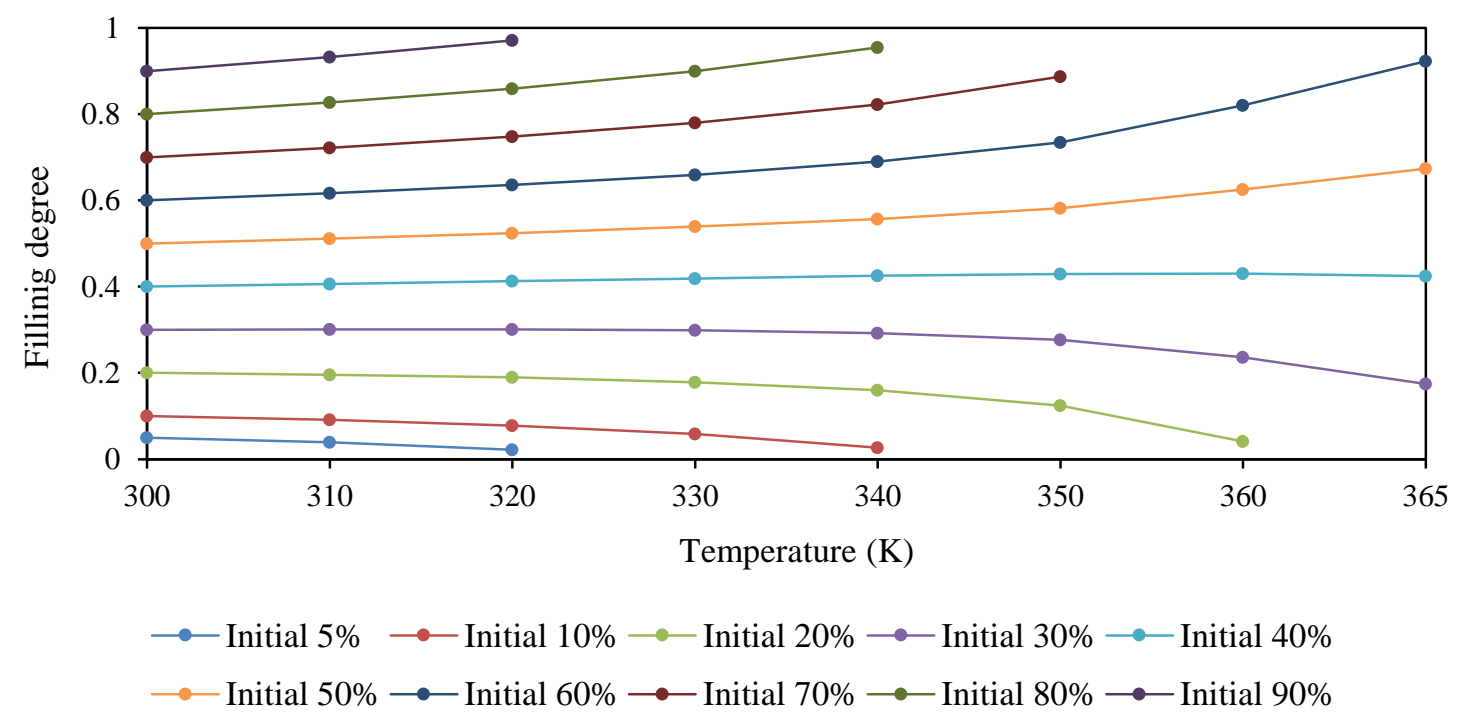

Fig. 3 - Non-linear behaviour of the relationship between filling degree and explosion temperature (propane, real gas behaviour and adiabatic irreversible expansion assumption).

The reliability of the new approach was also studied by using a full scale case. Bubbico and Marchini (2008) studied the explosion of a propane road tank $\left(13 \mathrm{~m}^{3}\right)$ during the transfer to 
a fixed storage vessel. A spill of liquefied propane was ignited, the tank was engulfed by flames and after $25 \mathrm{~min}$ it exploded. At the moment of the explosion $F D=8.4 \%$ (it had decreased significantly due to the continuous release) and the temperature of the propane liquid phase was $300 \mathrm{~K}$. From the analysis of the accident damages, the peak overpressure was determined at 20 and $30 \mathrm{~m}$ (Table 5). The study showed that the new approach also gives a good level of performance for predicting this full scale real case.

Table 5. Polynomial prediction vs. real values for a given propane BLEVE accident (Bubbico and Marchini, 2008).

\begin{tabular}{ccc}
\hline Distance (m) & New approach (Polynomial) $(\mathbf{k P a})$ & $\begin{array}{c}\text { Estimated from } \\
\text { accident damages } \\
\mathbf{( k P a )}\end{array}$ \\
\hline 20 & 7.6 & $5-6$ \\
30 & 4.8 & 3 \\
\hline
\end{tabular}

\subsection{Example of application}

A cylindrical vessel with a volume of $80 \mathrm{~m}^{3}$, containing liquid propane at room temperature $\left(20^{\circ} \mathrm{C}\right)$, undergoes a BLEVE due to fire engulfment; a loss of containment takes place through a safety valve. At the burst moment, the content temperature is $50{ }^{\circ} \mathrm{C}$ and the filling degree is $34 \%$. Estimate the overpressure $(\Delta P)$ at a distance of $100 \mathrm{~m}$.

Solution:

$F D=0.34$

$T=323 \mathrm{~K}$

Using the propane equation in Table 3 to find the mechanical energy per cubic meter $(e)$ :

$e=43.97-213.9 \cdot 0.34-0.152 \cdot 323+1.349 \cdot 0.34 \cdot 323-0.0004361 \cdot 323^{2}-0.002045 \cdot 0.34$ $\cdot 323^{2}+1.55 \cdot 10^{-6} \cdot 323^{3}=4.5 \mathrm{MJ} / \mathrm{m}^{3}$

Therefore, the total energy $E^{*}$ is:

$$
E^{*}=e \cdot V_{T}=4.5 \cdot 80=360 \mathrm{MJ}
$$

and the TNT equivalent mass is:

$$
m_{T N T}=\frac{\beta \cdot E^{*}(\mathrm{MJ}) \cdot 10^{3}}{4680}=\frac{0.4 \cdot 360 \cdot 10^{3}}{4680}=30.8 \mathrm{~kg} \mathrm{TNT}
$$


Next, the scale distance for $r=100 \mathrm{~m}$ is:

$$
\bar{R}=\frac{r}{\left(m_{T N T}\right)^{1 / 3}}=\frac{100}{(30.8)^{1 / 3}}=31.9
$$

By using the TNT curve (Casal, 2008), $\Delta P$ at $100 \mathrm{~m}$ is $3.6 \mathrm{kPa}(0.036 \mathrm{bar})$.

\section{Discussion and conclusions}

The prediction of the overpressure generated in a BLEVE explosion will always be subjected to some uncertainty, essentially due to the fact that only a fraction of the mechanical energy released in the explosion is invested in creating the overpressure. It can be assumed that between $50 \%$ and $60 \%$ of the overall energy released is required to break the vessel (ductile failure) and to eject the vessel fragments, but this percentage cannot be predicted in an accurate way; it will depend on different aspects, such as, for example, the way in which the vessel is heated, the influence of the welding, the condition (aging) of the vessel, etc.; the value $\beta=0.4$ seems to be adequate, taking into account the relatively good agreement obtained with the experimental values. Nevertheless, and even taking this into account, it is obvious that some methods give better predictions -closer to the real values- than others.

Of course, there will also be always some uncertainty related to the filling degree, which will depend on the time during which material will have been released through the pressure relief valve, or to the liquid temperature at the moment of the explosion (a temperature near the equilibrium with the set pressure of the pressure relief valve can be assumed). Nevertheless, these circumstances will exist as well for any other method which could be applied, this uncertainty being also found in many calculations of accidental effects when performing a risk analysis.

The new method proposed, based on the almost linear relationship between the released mechanical energy, the temperature at the moment of explosion and the filling degree, allows obtaining fairly good values in a quick and simple way. It does not require the substance thermodynamic properties (enthalpy, entropy, internal energy, etc.) and it only needs the rupture temperature and the filling degree to calculate the BLEVE mechanical energy and the resulting overpressure. The comparison of its predictions with the values corresponding to experimental data gives very positive results, this validating the reliability of the method. 


\section{Acknowledgement}

This work was supported by the Spanish Ministry of Economy and Competitiveness [Project CTM2014-57448-R, funded with FEDER funds].

\section{References}

Birk, A. M., VanderSteen, J. D. J., 2006. On the transition from non-BLEVE to BLEVE failure for a $1.8 \mathrm{~m} 3$ propane tank. J. Press. Vessel Technol, 128 (4), 648-655.

Birk, A. M., Davison, C., Cunningham, M., 2007. Blast overpressures from medium scale BLEVE tests. J. Loss Prev. Process Ind., 20 (3), 194-206. doi: dx.doi.org/10.1016/j.jlp.2007.03.001.

Birk, A.M., Heymes, F., Aprin, L., Slangen, P., Eysette, R., Lauret, P., 2016. Near field blast effects from BLEVE. Chemical Engineering Transactions 48, 283-288. doi: dx.doi.org/10.3303/CET1648048.

Brode, H. L., 1959. Blast wave from a spherical charge. The Physics of Fluids, 2 (2), $217-$ 229.

Bubbico, R., Marchini, M., 2008. Assessment of an explosive LPG release accident: A case $\begin{array}{llllll}\text { study. } & \text { J. } & \text { Hazard. } & \text { Mater., } & 155 & \text { (3), }\end{array}$ doi:dx.doi.org/10.1016/j.jhazmat.2007.11.097.

Casal, J., Salla, J. M., 2006. Using liquid superheating energy for a quick estimation of overpressure in BLEVEs and similar explosions. J. Hazard. Mater., 137 (3), 1321-1327.

Casal, J., 2008. Evaluation of the Effects and Consequences of Major Accidents in Industrial Plants. Elsevier, Amsterdam.

CCPS, 2010. Guidelines for Vapor Cloud Explosion, Pressure Vessel Burst, BLEVE, and Flash Fire Hazards, 2nd Edition. Wiley Subscription Services, Inc., A. Wiley Company, New York.

Crowl, D. A., 1991. Using thermodynamic availability to determine the energy of explosion. Plant/Operations Progress, 10 (3), 136-142. doi: 10.1002/prsb.720100306.

Crowl, D. A., 1992. Using thermodynamic availability to determine the energy of explosion for compressed gases. Plant/Opererations Progr., 11 (2), 47-49. doi: 10.1002/prsb.720110206. 
Hemmatian, B., Planas, E., Casal, J., 2015. Fire as a primary event of accident domino sequences: the case of BLEVE. Reliability Eng. Syst. Safety, 139, 141-148.doi: dx.doi.org/10.1016/j.ress.2015.03.021.

Hemmatian, B., Planas, E., Casal, J., 2017. Comparative analysis of BLEVE mechanical energy and overpressure modelling. Process Safety and Environmental Protection, 106, 138-149. doi: dx.doi.org/10.1016/j.psep.2017.01.007.

Johnson, D.M. , Pritchard, J.M. , Wickens, M.J., 1990. Large catastrophic release of flammable liquids. Comission of the European Communities Report, contract n. EV4T.0014.UK, 1990.

Laboureur, D., Heymes, F., Lapebie, E., Buchlin, J., Rambaud, P., 2014. BLEVE overpressure: multiscale comparison of blast wave modeling. Process Safety Progress, 33(3), 274-284.

Lemmon, E., McLinden, M., Huber, M., 2007. REFPROP: Reference fluid thermodynamic and transport properties. NIST standard reference database, 23(8.0).

Piñeiro, G., Perelman, S., Guerschman, J. P., Paruelo, J. M., 2008. How to evaluate models: Observed vs. predicted or predicted vs. observed? Ecological Mod., 216 (3-4), 316-322. doi: doi: dx.doi.org/10.1016/j.ecolmodel.2008.05.006.

Planas Cuchi , E., Salla , J. M., Casal , J., 2004. Calculating overpressure from BLEVE explosions. J. Loss Prev. Process Ind., 17 (6), 431-436. doi: dx.doi.org/10.1016/j.jlp.2004.08.002.

Planas, E. and Casal, J. 2015. BLEVE-Fireball. Handbook of Combustion. 1:21:1-25. WileyVCM. Weinheim.

Prugh, R. W., 1991. Quantitative Evaluation of "BLEVE” Hazards. J. Fire Prot. Eng., 3 (1), 9-24.

Smith, J. M., Van Ness, H. C., Abbott, M., 1996. Introduction to chemical engineering thermodynamics (5th Ed.). McGraw-Hill, Inc., New York.

\section{Nomenclature}

$e \quad$ Explosion energy considering the expansion of the pre-existing vapour plus the vapour generated in the flashing of the liquid, $\mathrm{MJ} /\left(\right.$ vessel $\mathrm{m}^{3}$ )

$E^{*}$ Explosion energy considering the expansion of the pre-existing vapor plus the vapor generated in the flashing of the liquid, J 
FD Filling degree, $\% / 100$

$m_{T N T}$ Equivalent mass of TNT, $\mathrm{kg}$

$r$ Distance between the center of the explosion and the point at which the overpressure has to be estimated, $\mathrm{m}$

$\bar{R} \quad$ Scaled distance, $\mathrm{m} \cdot \mathrm{kg}^{-3}$

$T$ Temperature of the vapor in the vessel just before the explosion, $\mathrm{K}$

$V_{T} \quad$ Total vessel volume, $\mathrm{m}^{3}$

$\Delta P$ Explosion peak overpressure at a given distance, $\mathrm{kPa}$ or bar

Greek Letters

$\beta \quad$ Fraction of the explosion energy converted into blast wave, -- 